\title{
NOTAS SOBRE EL ESPAÑOL HABLADO EN LA ISLA DE LA GRACIOSA (CANARIAS ORIENTALES)
}

\author{
A Sebastián Sosa
}

Introducción

I. En el mes de mayo de I965 llevé a cabo una encuesta en la Caleta del Sebo, localidad de la isla de La Graciosa, que, en el futuro AIEICan representará la modalidad lingüística de ese islote dentro del conjunto de las Islas Canarias.

El poblado tiene 423 almas ${ }^{1}$ y con Pedro Barba ${ }^{2}$ constituye la

1 Segín el Diccionario Corográfico de España (censo de 1940). La población ha debido aumentar posteriormente, según consta en mi Cuestionario del ALEICan. página I9.

En el Ayuntamiento de Teguise, al que juridicamente está adscrito el islote, me facilitaron los siguientes informes sobre la población y construcciones de la Graciosa:

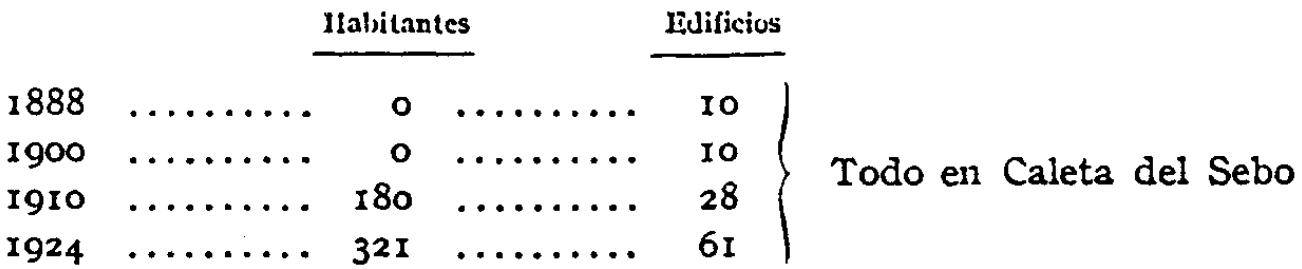

$$
\begin{aligned}
& \text { 1940: (hubo censo en dos núcleos de población) } \\
& 427 \ldots \ldots \ldots .75 \text { (Caleta del Sebo) } \\
& 65 \ldots \ldots \ldots . .13 \text { I3 (Pedro Barba) } \\
& \text { I955 } \ldots \ldots \ldots \ldots \quad 557 \ldots \ldots \ldots \text { I } 27 \text { (Caleta del Sebo) } \\
& 82 \quad \ldots \ldots \ldots .28 \text { (Pedro Barba) } \\
& \text { I965 } \ldots \ldots \ldots \ldots \text { 712 } \ldots \ldots \ldots \text { I77 (Caleta del Sebo) } \\
& 95 \quad \ldots \ldots \ldots .20 \text { (Pedro Barba) }
\end{aligned}
$$

Antes de estos establecimientos fijos, las gentes de Teguise iban a La Graciosa a recoger la barrilla y a dejar las crias, que crecian sin sus madres, y asi no mermaban los escasos pastos de Lanzarote. Una y otra actividad estaban reglamentadas. El abandono del ganado se hace todavia en la isla de Fuenteventura: he visto en la península de Jandia alguna bandada de guirres cerniéndose sobre corderos recién nacidos, a los que sacrificaban cruelmente.

- 62 habitantes según cl mismo Diccionario. Pedro Barba fue un personaje importante en la antigüedad hispálica de las Islas. 
totalidad de núcleos habitados que hay sobre los 27 kilómetros cuadrados de la isla. La organización administrativa de estos lugares depende de la villa de Teguise, antigua capital de Lanzarote, adormecida hoy en un paisaje impresionante.

2. La isla, situada al norte de la de Lanzarote, ha carecido siempre de importancia: ni una sola vez se aduce en la monumental obra de Rumeu de Armas ${ }^{1}$. Si acaso, alguna referencia puramente descriptiva en el P. Abreu Galindo, y desde su Historia pasó rodando a otros cronistas: "La isla de $\mathrm{I}_{a}$ Graciosa se llamó así porque, como está más cercana a la isla de Lanzarote, forma una canal muy agradable a la vista, entre la una y otra islan ${ }^{2}$.

3. No tengo datos sobre el momento de la población de La Graciosa. Es, desde luego, anterior a los 30 ó 40 años que muy vagamente dio algún historiador local. Baste pensar que uno de mis informadores tenía 62 años y su madre ya había nacido en la Caleta. Es cierto - sin embargo- que la isla ha estado siempre despoblada, pues en este sentido hau hecho hincapié los escritores antiguos. Así, Gaspar Frutuoso ${ }^{3}$ -escribe en I590- dice que "Graciosa é terra despovoada"; asi Fr. José de Sosa -escribió en I678-, que sin dar con exactitud el tamaño relativo de La Graciosa, Alegranza y Montaña Clara, insiste - sin embargo- una y otra vez diciendo que La Graciosa está despoblada 4, por más que sirva upara criar gauados y para coger pájaros». Las cosas han debido cambiar mucho, pues ganado no hay, salvo unas escasas cabras, y los pájaros ni se ven ni se oyen (vid. nota I en la p. 293 donde se puede inferir qué debemos entender por 'criar ganados').

En el Diccionario de Madoz ${ }^{5}$ no se encuentran otras indicaciones que las descriptivas de la isla, pero sin hablar para nada de su población. Es más, en el repertorio faltan los topónimos Caleta del Sebo y Pedro Barba, lo mismo que faltan también en las Cartas corográficas de Benito Chías y Carbó, insertas en el tomo de mapas de la España Regional

1 Piraterias $y$ ataques navales contra las Islas Canarias. Madrid, 1947-1950. Estos tres tomos (en cinco volúmenes) ofrecen mucho más de lo que su titulo indica.

2 FR. J. DE ABREU Gal.INDo. Historia de la conquista de las siete islas de Canarias. Edición critica de A. Croranescu. Santa Cruz de Tenerife, 1955, p. 52.

3. Las Islas Canarias, apud "Irontes Rerum Canariarum, XII, La Laguna, I964, página 7.

- Topografía de la Isla de Gran Canaria (edición de r943), pp. 7, 87-88;

- Diccionario Geogrdfico-Estadistico-Histbrico de España y sus posesiones de Illtraniar. Madrid, desde 1845 . 
(Barcelona, s.a.). Según he dicho anteriormente, en I940 se documentó oficialmente la puebla de los dos lugares.

4. Hoy la Caleta y Pedro Barba son dos pueblecitos de pescadores. Pequeñas embarcaciones dedicadas a trabajos costeros constituyen la exigua flotilla de la isla. Fuera de la pesca, no hay otros recursos que puedan ayudar al sustento de las familias que se albergan en este nuundo. Pescado y cabras facilitan unos medios elementales de subsistencia. El resto - todo- debe traerse desde Lanzarote. Y con Lanzarote - de donde salió- se relaciona la modalidad dialectal que vamos a intentar describir. Ia lengua - una vez más- no es sino un aspecto de hechos sociales más amplios.

5. El análisis que sigue se basa, como queda dicho, en un Cuestionario de Atlas de Canarias. Son materiales que un dia aparecerán cartografiados. Ahora los ordeno con un criterio nuy diferente. El que pertenezcan a un Atlas Lingüístico justifica su carácter limitado, pero, a pesar de esa limitación, dan unos informes bastante nutridos sobre hechos y procesos. Indirectamente, piedra de toque del valor de los Atlas para estudiar la biología lingǘstica, incluso cuando desgajamos los materiales allegados de la comparación coherente para la que se recogieron.

6. Como queda dicho, la vida de La Graciosa está totalmente condicionada por salidas a Lanzarote. Administrativamente, Caleta del Sebo depende de la Villa de Teguise, pero sus comunicaciones - siempre irregulares- se hacen con un "barquillo" o una "falúa" desde Arrecife (capital de Lanzarote) o cruzando la lengua que separa las dos islas. Al volver cargadas con enormes bultos sobre sus cabezas, las gracioseras descienden por una senda de cabras y, en llegando a la orilla, encienden una hoguera, que sirve de llamada para que un bote venga a buscarlas.

7. Tuve dos informantes del islote; ambos del principal núcleo de de población, Caleta del Sebo, pertenecian a las actividades habituales de las gentes de la localidad: el hombre era marinero y la mujer, se dedicaba a tareas domésticas. Fueron:

I) Marcos Romero Páez, de 62 años, analfabeto. Habia hecho el servicio militar en Las Palmas de Gran Canaria y en Arrecife (durante catorce meses). Había nacido - lo mismo que su mujer y que su madreen la Caleta del Sebo; su padre, sin embargo, era de Alegranza, islote más pequeño y septentrional donde sólo vive una familia. Sus viajes se han reducido a las salidas obligadas por su profesión.

2) Antonia Batista Morales. Tenía I8 años; era, como he dicho, de la Caleta, igual que sus padres. No habia salido del pueblo y tenía instrucción primaria. 
8. Mis dos informadores alargaban extraordinariamente las vocales acentuadas: ro:pa, la:zu, bla:ncur, ye:gua ${ }^{1}$; es este un rasgo que he anotado en mis encuestas de 'Tenerife ${ }^{2}$, Gran Canaria y Lanzarote. Acaso -en cuanto a duración de las vocales acentuadas- el habla de I,a Graciosa coincida con Lanzarote, más que con las otras islas.

\section{Articulación de la $\mathrm{O}$}

9. La -o final era extraordinariante cerrada .Con frecuencia no se percibia sino $u$. Sin embargo, entre el habla del hombre (citaré $H$ ) y la mujer (M) había algún rasgo distintivo. El hombre mantenia en muchos casos la o cerrada (peazo 'pedazo', niño, susio, arco, enreạ 'enredado', añublạ 'nublado') mientras que M, en idénticas circunstancias, tenía -u (pedazu, niñu, suciu, alcu, enreau, añublau). Como en todas las hablas innovadoras que no han logrado nivelarse, hay numerosos casos de polimorfismo espontáneo: el hombre dijo una vez machu y otra, macho; una arbo y otra, arbu; una, engohto y otra, chtrechu. Amén de articular en alguna ocasión una vocal neutralizada, $\delta$, como se oyó en se'ts 'cesto', arbó 'árbol', curoillas 'arrodillado', golgucllo 'gaznate, garganta de los animales', etc. En la mujer no anoté sino $0,0, u$.

ro. El cierre de la -o final se cumplía siempre, incluso cuando la vocal quedaba en posición final absoluta por pérdida de una consonante. Entre nuestros dos informantes podía haber discrepancias en cuanto a la realización fonética del sonido, pero la tendencia al cierre se documenta en ambos: dop peazo (H) udoh pedazu (M), loh macho (H) viloh machu (M), doh lazu (H, $\mathrm{M})$, unoh niño $(\mathrm{H})$ sunoh niñu $(\mathrm{M})$, alcọl 'alcohol' (H) varco (M), arco (H) uralcu (M), log garbanzo 'los garbauzos' (H) cslo harbanzu (M). En la conjugación, el hombre (único informante a quien le pregunté) dijo collemọ 'cogemos', colimo 'cogimos', venimo

1 Para evitor dificultades de composición, transcribiré fonéticamente sólo el tratamiento a que me refiera en cada párrafo.

2 M. Alvar. El español hablado en Tenerife. Madrid, 1959, § тo. De ahora en adelante, citaré $\longrightarrow$ simplemente- Tenerife. 
'venimos', asemo 'hacemos', etc., coincidiendo con las formas sustantivas en os $^{1}$.

II. Consideración aparte merece la final -ón. La nasal se articula como velar relajada o desaparece, nasalizando a la vocal, pero ésta

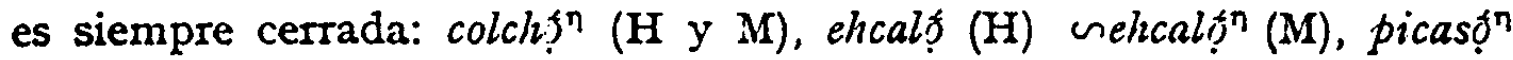
$(\mathrm{H})$, camisọ ${ }^{\eta}(\mathrm{H})$, etc. ${ }^{2}$.

I2. En cualquier otro caso, la 0 tendía a articularse cerrada, fuera acentuada o no. En posición in i c i a l a b s o 1 u $\mathrm{ta}$, si la o llevaba el acento, el cierre se producía con independencia de que la sílaba fuera libre (obra, H y M; oyo, id.; ocho, id.) o no (ombre, H y M). También recogi la misma articulación, en posición in i ci a 1 , acentuada, pero precedida por una consonante ( $m o \varphi h u, \mathrm{H}$ y M; bota, $\mathrm{M}$ ), y en posición postóni c a (árbọle, 'árboles', H y M).

13. Como en otras zonas del dominio hispánico, el español de Ia Graciosa, tiende a la articulación cerrada de la $o$, cualquiera que sea su posición dentro de la palabra. Sólo se exceptúan algunos casos en los que -como en castellano- la consonante trabante abre a la vocal anterior (engohtu 'angosto, estrecho', gordu), pero, incluso en ellos, las nasales cierran a la vocal anterior en vez de abrirla.

Nuestro informador $M$, a pesar de su juventud e instrucción, en éste, como en otros casos que veremos, poseía un grado de dialectalización superior al del hombre. La vocal - $u$ aparecía en su habla con una insistencia mayor que en el otro sujeto.

\section{Articulación de la $\mathrm{E}$}

14. La -e final también se cerraba, pero de modo menos sistemático que la -0 . Es una situación en todo paralela a la que se cumple en otras áreas del español trasplantado: en Méjico, por ejemplo. No obstante, la tendencia a articular la -e cerrada era ostensible. La mujer solía articular una vocal todavía más cerrada que la del hombre. Así aseite $(\mathrm{H})$ saceité $(\mathrm{M})$, nochì $(\mathrm{H})$ unochi $(\mathrm{M})$, vinagre $(\mathrm{H})$ svinagri $(\mathrm{M})$.

1 La -o se cierra en otras islas, pero no creo que en el grado que aqui transcribo. Al menos no es tan cerrada en Tenerife, Gran Canaria, Fuerteventura y algunos puntos de Lanzarote (el norte de esta isla coincicle con La Graciosa) en los que he hecho encuesta directa. Cfr. Tenerife, $\S 8 \mathrm{~b}$. Encuestas posteriores me ban perwitido encontrar un tratamiento igual al de La Graciosa en alguna aldea grancanaria (Atalaya de Santa Brfgida) y en todos los puntos de Ia Gomera donde he trabajado (San Sebastián, Vallehermoso, Fil Cercado, La Caiera, Ios Granados, Alajeró, Targa).

2 Tenerife, $\S 8 \mathrm{~d}$. 
Otras veces, MI articulaba con vocal cerrada, o tendiendo a ella, casos en los que el hombre tenía vocal media (hombren hombré, mueble csmue$b l \hat{b})$. Ira mujer presentaba $-i$ en las formas enclíticas del pronombre (d́ali 'dale', dimi 'dime', mándeli 'mandele'), que no anoté en el habla de $\mathrm{H}$. Sin embargo, contra estos hechos constun otros como la vocal cerrada de $\mathrm{H}$, doude la mujer la tiene abierta (parés-paré ${ }^{1}$ ), el timbre más cerrado de $\mathrm{H}$, dentro de la común tendencia de mis dos informantes: padre (H) upadré (M) o, por último, la vocal cerrada de $\mathrm{H}$ donde la mujer la tiene media (Carmé $\backsim$ Carme). Cierto que estos casos son poco significativos: pueden ser hechos motivados por una vacilación mor: fológica o realizaciones momentáneas de un signo que, normalmente, es - $\ell$. Creo que permanece en pie la tendencia, común en $\mathrm{H}$ y en $\mathrm{M}$, a cerrar la -e fival y cl cumpliniento, en $M$, de los grados de menor abertura (llega a $-i$ ). Proceso, pues, en todo paralelo al de $-0>-u$, aunque sin alcanzat su intensidad.

15. Esta tendencia $-e>-i$ se documenta alguna vez en los casos de pérdida de la consonante implosiva. Así diente 'dientes' ( $M$, frente a diente 'dientes' (H), Carmé (H), bebẹ (M) unbebel (H), paré (H), brimbẹ 'mimbres' (H), mueble 'muebles' (M), lune 'lunes' (H). Pero también hay almiré. ( $\mathrm{H}$ y. M) y lente 'lentes' (H).

El hombre, al responder a las formas verbales en -es, pronunció una vez .-e (sale 'sales'), mientras que lo normal es el resultado polimóffico, e indistinto, de las terminaciones que en castellano acaban en $-e s, 0$ cn $-e$.

I6. La terminación -cn se pronuncia $-\tilde{e}^{\eta}$ (beletêt $e^{\dagger}$ sartét $)$, en el verbo, $e^{\eta},-\tilde{c}^{\eta}, \tilde{c}$.

17. La articulación de la $-e$ en el habla de $L_{a}$ Graciosa tiende a ser cerrada, no con la misma intensidad con que $-0>-u$, pero sí de un modo claro $y$, documentalmente, repetido. También en esta ocasión el informante $\mathrm{M}$, el más joven e instruído, parece abocar a soluciones de un dialectalismo extremo; en tanto que $\mathrm{H}$, permitiendo comprobar la misma tendencia, se limita dentro de unas realizaciones más tímidas.

1 El testimonio puede iuterpretarse de otro modo, ya que en el habla del hombre se opuso el singular pare, al plural paré; mientras que la mujer -acaso presionando sobre ella la lengua de la escuela- dijo paré para singular y plural, se corrigió en el segundo caso (diciendo pared $\dot{\text { ) }}$ para repetir de nuevo paré como 'paredes'. Hubo, pues, en ella la conciencia de una forna distinta de la familiar, $y$, en la inseguridad de sus conocimientos, $M$ dio unas respuestas que no se pueden considerar más que como vacilantes. Compárense estos hechos, con el de la pregunta 49 del cuestionario: pię: (H) upiê:: (M) 'pie', pię: (H) upie: (M) 'pies'. Ahora es $\mathrm{H}$ quicu neutraliza la oposición. 
Con independencia del proceso articulatorio, la realización fonética del fonema $[e]$ como [e] o [i] es indiferente a la naturaleza del sistema, puesto que $[e],[i]$ no se oponen a $[e] \circ[e]$. Se trata pues de la plural realización fonética de $[e]$ o, dicho de otro modo, $\dot{e}, e, \dot{e}, i$ no son sino alófonos de un fonema único $[e]$.

18. La pronunciación de la $a$ era más velar que la castellana. Según se ha anotado alguna otra vez en el español insular ${ }^{1}$. Sin embargo, el rasgo más característico del tratamiento de la a ocurría cuando la vocal estaba en posición final absoluta y era precedida por una palatal acentuada; en tal caso, la - $a$ pasaba a $\ddot{a}$. Así:

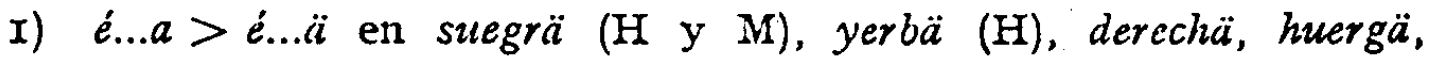
grietä, diretä 'directa', rettä 'recta' (todos en $\mathrm{H}$ ), docienlä (M). Como se ve, el rasgo es independiente de la situación de é (en diptongo o no) y se documenta en $\mathrm{H}$ y $\mathrm{M}$, aunque - tal vez- con preferencia en el varón. La palatalización de la - $a$ no se cumple cuando está acentuada: quehá 'quijada' (H), albiá 'albear' $(\mathrm{H})$.

2) i...a > i...̈̈: gallinä $(\mathrm{H})^{2}$, sillä ( $\mathrm{H}$ y $\left.\mathrm{M}\right)$, comiä 'comida' (M), mordiä, canillä, fatigä, morriñä, etc., (en $\mathrm{H})^{3}$. Los casos recién transcritos nada tienen que ver con las formaciones del plural, y la palatalización se cumple aunque en la palabra no aparezca ninguna consonante palatal.

3) Es importante consignar que palatalizaciones de este tipo (aunque en un campo más dilatado) se dan en el gallego-leonés de Ancares y en los dialectos portugueses 4: no puedo establecer dependencia entre todos estos fenómenos, pues -aunque harto conocida la influencia portuguesa! en Canarias- necesitariamos muchos más materiales (lingüísticos, históricos, sociales) antes de pronunciarnos con seguridad de éxito.

1 Tenerife, $\$ 5, \mathrm{x}$.

2 H dijo gallina (singular) y gallinä (plural), mientras que $\mathrm{H}$ pronunció - gallinä (singular) y gallina (plural). 'Tal vez en este polinorfismo actuó la acción de la $-s$ del artículo sobre la sonora inicial: lah gallina (H) $\backsim$ do hallina 'dos gallinas' (M). nario.

- Téngase en chenta que a MI sólo le pregunté la parte fonética de mi cuestio-

- Vid. D. Alonso y V. Garcha YeBra, Ll gallcgo-leonés de Ancares y su interés para la dialectologia portuguesa. Actas do III Colóquio Internacional de Estudos Luso-brasileiros* Lisboa, 1959. t. I. pp. 331-337. 
I9. Ell plural de los sustantivos en $-a$, tras la pérdida de la $-s$, daba lugar a diversos resultados con o sin acción sobre la vocal:

r) ne u $\mathrm{t}$ a l i z a c i ó $\mathbf{n}$ de las posibilidades distintivas: la ropa $=$ = 'la ropa, las ropas' (en H y M), papa (sing. y pl. en M), bota 'bota(s)' (H y M), vaca 'vaca(s)' (id.), llama 'llama(s)' (M), yegua (M).

2) pa lat a liz a ción de la a: lah gallinä (H), docientä dos-

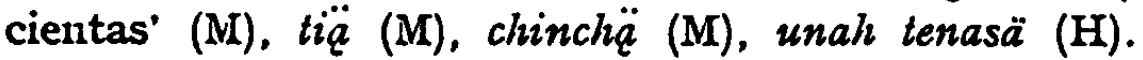

3) a bertura de la vocal: papq (H), liendra, chinchq, llamq, yegua (id.).

20. Una vez más los resultados polimórficos asoman por doquier. La abertura de la vocal, que parece darse únicamente ell el hombre, debe ser un eco de la aspiración de la $-s(>-h)$, puesto que el informador $H$ mantiene de vez en cuando la $-h$ (con mayor o menor grado de relajamiento) como íudice del plural (clinelz) o no (puh 'pus', vagueh 'pereza'). La palatalización, atestiguada en $\mathrm{H}$ y $\mathrm{M}$, pero con mayor frecuencia en la mujer, nos situaría ante hechos paralelos en todo de los del español meridional (Este de Andalucía, sobrc todo); mientras que la neutralización singular uplural hace pensar en el andaluz occidental. Bien a las claras se ve que hay pluralidad de normas en colisión; si la lengua llega a nivelarse, una de ellas tendrá que eliminar a las otras. Pero, entre tanto, vemos que el habla se debate por lograr un instrumento expresivo (el indice de pluralidad) que se le escapa. Es posible que alguno de estos medios (abertura, palatalizaciôn) se logre como morfema de plural, pero también es posible que ninguno alcance tal fin, o que se anule definitivamente la oposición uno cnvarios. Entonces la a se mantendrá sin ninguna clasc de desdoblamientos. Ambas posibilidades existen y se dan en el español meridional, pero, aun en los casos en que un rasgo ha alcanzado alli valor fonologico, la falta de nivelación basada en la cultura ha hecho que coexistan varias normas en colisión por más que una predomine sobre las otras. En el español de La Graciosa -minúscula parcela de un inmenso dominio- existen no menos de cuatro tendencias (signo cero, $a, \ddot{a}, \ddot{a})$ y todas se muestran, en los materiales de que disponemos, con posibilidades de coexistir polinórficamente en los hablantes. Esta posibilidad de polimorfismo puro es la que -a mi modo de ver - hace que ninguna de las realizaciones fonéticas posea hoy caracter fonológico; que acaso nunca llegue a poseerlo. $Y$ que el signo de plural tenga que seguir expresándose por indicios de otras procedencias.

2r. En el momento oportumo señalaré la acción de las consonantes uasales. Ahora quiero apuntar, por cuanto pudiera tener de rasgo fonológico, el tratamiento de la terminación -an. En los sustantivos, 
mis notas señalan la nasalización de la vocal con mantenimiento de la

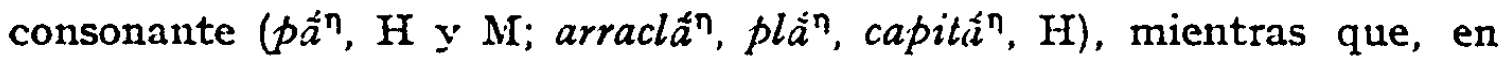
el verbo, la abundancia de formas correspondientes a las terceras personas del plural, nos permitirán ampliar los informes de tan parcos materiales (vid. § 34).

\section{Articulacion de las consonantes}

22. De las oclus iv a s $(p, t, k, b, d, g)$ merece apuntarse cierta tendencia a la neutralización de $k$ y $g$ que se atestigua en $\mathrm{H}: k^{g} a z u e l a$, $k^{8}$ aracolillu, trik'ete [sic] 'trinquete', $g^{k}$ itarra. Estos ejemplos -en verdad- no son muchos, pero me parecen harto sintomáticos: la investigación con cuestionario condiciona siempre la tensión con que se articula la respuesta; sobre todo, en posición inicial absoluta es más difícil obtener un sonido no sometido a esta limitación. A pesar de ello, se han documentado dos casos de sonorización de la $k$-inicial; uno de $k$ interior y otro en el que la $k$ - ha pasado definitivamente a $g$ (gometa). Por el contrario, la sonora se ha ensordecido parcialmente en otra ocasión y se ha hecho sorda ell ehcarro 'gargajo' y kitarra. Con los datos de que disponemos se ve, claramente, que hay tenclencia a la sonorización de la $k$ oclusiva e incluso a cierta neutralización de la oposición sonoridad $u$ sordez en las consonantes velares. Algún caso ha significado la total sustitución de $k$ por $g$, o de $g$ por $k$, pero la mayoría hace pensar en la creación cle un archifonema. Lil fenómeno, por difuso que se muestre en apariencia, coincide con tendencias del mismo tipo que se están cumpliendo tambien en Andalucia 1.

23. In cuanto a la articulación de la $F$ debo señalar que los informadores la pronunciaban como bilabial y no como labiodental: quera, фuente, pregá, фlor, plore, pechillo (todos en H y M), фi, фatiga, garrạón, goфiz (en H). Como se ve, el carácter bilabial de la $\Phi$ no depende de la articulación del wau siguiente, sino que consta en cualquiera otra posición.

24. I a $d$ se perdía en posición inicial, bien que sólo en los conocidos casos de confusión de prefijos (des- $\mathrm{x}$ es-): estrosador, ehpehá 'despejar', ehcarro (todos en $\mathrm{H})^{2}$. Es mucho más frecuente la pérdida de $-d$-intervocálica, que se cumple en el habla de $\mathrm{H}$ y $\mathrm{M}$, cualquiera

1 Vid. G. Salvador, Nellivalización G-, $K-$ en el español. Comunicación expuesta en el XI Congreso Internacional de Jingüistica y Iilologia Ronánica. Madrid, 1965.

2 Tenerife, $\S \mathrm{12}, \mathrm{x}$. 
que sea la naturaleza de las vocales que están en contacto con la fricativa: peazo (H) upedazu (M), deo (H, M), enreao $(\mathrm{H})$ nenreau $(\mathrm{M})$, comia $(\mathrm{H}, \mathrm{M})$, anublao $(\mathrm{H})$ vamublau $(\mathrm{MI})$, bria $(\mathrm{M})$, ruea. $(\mathrm{H})$ urueda $(\mathrm{M})$, quehá 'mandíbula', enroillan 'arrodillado', petur 'jorobado', etc., (H). A estos ejemplos hay que añadir el testinonio de media ocena, documentado ell $\mathrm{H}^{3}$.

\section{La S y la $\mathrm{H}(<-\mathrm{S})$}

25. Como he descrito en otros casos ${ }^{2}$, la $s$ es predorsal, fricativa, sorda. Se articula, cuando va en posición implosiva, con una gran tensión. No observé diferencias, en cuanto a la pronunciación, entre $\mathrm{H}$ y $\mathrm{M}$. E.1 seseo se documenta en los dos informadores.

26. Iin posición implusiva, la $s$ se aspira en una faríngea o laríngea cuya condición (dental, nasal, etc.) depende de los sonidos prọ́ximos. Consideraré dos casos:

I) ell posición in terior:

a) Cuando la $s$ va seguida de una consonante b i l a bi:a 1 se asimila a la $p$, pero manteniéndose la reduplicación (eppchu, $\mathrm{H}$ y $\mathrm{M}$; $e^{p}$ pañó, $\mathrm{H})$, o bien la asimilación es total, y desaparece todo resto de la aspirada (rebalar) ${ }^{3}$.

b) Si la consonante siguiente es una d e $n t a 1$, pueden darse una serie de procesos que van desde la simple aspiración (ce $e^{h} t, \mathrm{M}$; dilut $t u$ 'disgusto', $\mathrm{H} \mathrm{y} \mathrm{Mr}$; cngohto, H; chtrechu, H y M; $e^{h}$ trosador, H) hasta la total asimilación (prutituta, H), pasando por la reduplicación (se'to, lete 'este', H). El seseo en un caso, y, en otro, la articulación ciceante hacen que en un ejemplo de $-s c-(-s \theta$ - en la lengua literaria) que poseo haya fusión de las dos consonantes: dosienta (H) undocientä (M).

c) I a $l$ no modifica en nada la naturaleza de la aspiración. Sin abundar mis datos, puedo señalar muhlo (H y Mis), ihla (H) 4 .

d) En cuanto a las vel a res, $-s k$ - pasa a $-h^{h}$ - en los dos informantes ( $m o^{h} c a, c^{k} c o b a, e^{k} c a l o ́ n$, etc.), mientras que -sg- se ha perdido como elemento bifonemático en muhu 'musgo' (H y M), di $i^{k} u h t u$ 'disgusto' (id.), fiha 'fisga'. (H) ${ }^{5}$.

$1 \quad$ Ib., $\$ \mathrm{I} 2,2$ y ID. CA'SAI,Axi, El español en Canarias, en Presente y futuro de la lengua española. Mladrid, 1964, t. I, p. 24 (citaré, CATAI.AN).

2 Tenerife, $\$ 17$.

3 Vid. Tonirife, $\$$ 20, I-2, y Catar,ís, p. 245.

- Tenerife, $\$ 22$.

- 1b., \$24. 
e) En contacto con las nasales, la $s$ se continua en una aspirada

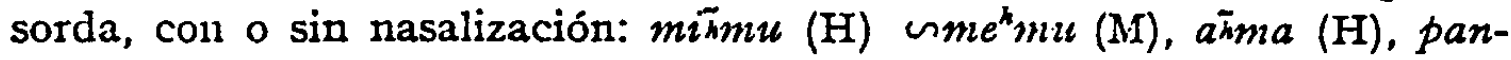

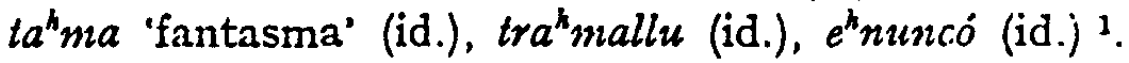

2) En posición $f$ in a 1:

a) cuando la palabra. siguiente empieza por consonante, los materiales recogidos arrojan los siguientes datos:

b) $-s+p-:$ aspiración (do pedazu, M; tre papa 'tres patatas', M; $d o^{h}$ patada, H) y reduplicación (do pedazo, $\mathrm{H} ; l a^{p}$ papa, $\left.\mathrm{H}\right)$.

c) $-s+b-:$ aspiración de la $s$ y $b$ oclusiva $\left(d o^{h} b a c a, M\right)$; reduplicación, manteniendo la $b$ oclusiva (la bria, $\mathrm{M}$; do bota, do brimbe, do $o^{b}$ baca, todos en $\mathrm{H}$ ), aspiración con ensordecimiento parcial de la $b$ ( $d o^{h}$ $\left.b^{\varphi} a c a, M\right)$ y eliminación de cualquier eco de la $-s$ originaria, pero sin que la $b$ se haga fricativa (dó bota, M) ${ }^{2}$.

d) $-s+\varphi-:$ asimilación total de la $-s>h$ : la plore (H y M).

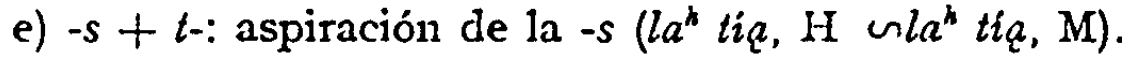

f) $-s+d$-: fuerte interdentalización de la $d$, asimilando a su punto de articulación la consonante anterior (lo diente, unod ateo, $\mathrm{H}$ ) o ensordecimiento parcial de la dental, con absorción de la $-s>h$ (lo ${ }^{\theta}{ }^{\theta}$ iente, dó $\left.t^{\theta} d e o, M\right)$. En bueno día, 'buenos dfas', $\mathrm{H}$ y $\mathrm{M}$ coincidieron en el resultado muy interdental de la $\vec{a}$ y pérdicla de la $h^{3}$.

g) -s $+\lambda-$ : la solución normal (H y M) es ${ }^{h} l:$ do lazu, la liendra, la lente.

h) -s + s-: las dos consonantes iguales se reducen a una: do se to $(\mathrm{H})$. Si se mantiene la pronunciación postdental de la $\theta$, la $-s$ no deja rastro: do $\theta e^{h} l o(\mathrm{M})$.

i) -s + r-: da siempre asimilación de la silbante a la vibrante, aunque varía el grado: unas veces es con reduplicación (la- riıe(d)a, $\mathrm{H}$ y M) y otras con asimilación total (la riendla, H).

j) -s + consonante p a 1 a $t$ a 1 : cuando ésta es $l l \circ \mathrm{ch}$, los dos informantes aspiraron la $s$ y mantuvieron inalteracla la palatal (la $a^{k}$ chinchq, - $\ddot{a}$; la $a^{k}$ llama, $\left.-a\right)$; por el contrario, el resultado de $-s+y$ - fue distinto: el hombre pronunció la ${ }^{h}$ yegua y la mujer la ýegua (con $\hat{y}$ africada).

k) $-s+k-$ proporciona tratamiento múltiple: aspiración de la $-s$ (l $\left.a^{h} c a^{n} n e, \mathrm{H} ; l o^{h} c l i n e^{k}, \mathrm{H}\right)$, o asimilación completa (la $\left.c a^{k} n e, \mathrm{M}\right)$.

1) $-s+g-:$ si la consonante velar es sonora, la evolución de la $-s$ puede manifestarse dentro de unos límites muy amplios. Desde la re-

$1 \quad I b ., \S 25$.

2 Cir. cl esquama de Tencrife, $\$ 20,4$.

- Difieren estos datos de los que recogi en Tenerife, $\$ 2 \mathrm{r}$.

1 Cfr. Tenerife, §2.3. 
duplicación de la $g-$, manteniendo su carácter oclusivo (lo garbantọ, unos guevo, H), hasta la aspiración secundaria de la $g$ (dó hallina, M; lo harbanzu, M; lo hranu, H y M; uno huevu, M). Aunque el tratamiento parece separar con frecuencia el habla de mis dos informantes, alguna vez coinciden ambos en la realización neutralizada de $g$ y $h: l a g^{k}$ allinä (H), uno g $g^{h}$ uevu (M) ${ }^{1}$.

m) $-s+$ in a s a l: se realiza como "nasal (lok macho, H y M; $l 0^{k}$ mueble, id.; unok niño, id.) o con eliminación de la aspirada (buena noche, $\mathrm{H}$ y $\mathrm{M}$ ).

27. El tratamiento de las dos series de fenómenos anteriores ( $-s+$ cons.- en una nuismia palabra; $-s+$ cons.- en palabras diferentes) permite establecer los siguientes esquemas:

I) La $s$ ante consonante $\mathrm{b}$ i 1 a b i a 1 sorda se aspira o reduplica; mientras que, ante bilabial sonora, el tratamiento es de mayor complejidad, puesto que puede haber aspiración, asimilación total o parcial ensordecimiento de la $b$. Nunca hay, sin embargo, fricatización de la bilabial. Los datos de que dispongo no son excesivamente abundantes y no permiten establecer una oposición cierta entre H y $\mathrm{M}$.

2) I a $s$ ante d e $n \mathrm{t}$ a 1 sorda se realiza como aspirada, como reduplicación relajada o como signo cero. Aun teniendo en cuenta la limitación de mis materiales ( $y$ su diferente densidad en las dos series que cousidero), la mujer parece más propicia a la solución ${ }^{h} t$; en tanto las otras predominan en $\mathrm{H}$. Cuando la consonante explosiva es la $d$, hay una grado de fuerte interdentalización que, en $M$, va acompañado de ensordeciniento ${ }^{2}$.

3) En cuanto al tratamiento de las vela res lo más notable es la metafonía -sg- $>h$, cumplida en mis dos series, y muy intensa eu M. El progreso está lexicalizado en algún hecho de lengua, donde ya no se siente la existencia de un grupo originario (mulku, fiha). Por lo demás, si se documeuta la reduplicación de $g$, es siempre con carácter oclusivo y no fricativo. Fin este caso, el habla de la mujer parece nucho más adelantada que la del hombre.

4) Otros tratamientos o son idénticos en ambas series o se basan en tan parvos materiales, que no se pueden ordenar en unas conclusiones.

2S. El tratamiento de la $s$ implosiva es el mismo cuando la $s$ va seguida de consonante en la misma palabra o en una palabra distinta. Los datos de que dispongo, permiten señalat dos hechos lingüísticos diferentes: uno, referido a la sociologia; otro, a la biología del dialecto.

1 Cfr. Tencrife, \$2.4.

- Muy otra es la suerte de -si-en Tenerife, \$2I. 
Por lo que respecta al primero, M, más joven y con mayor instrucción que $\mathrm{H}$, muestra, sin embargo, un grado más intenso de dialectalización. Como he comprobado en otras ocasiones ${ }^{1}$, el habla de la mujer está menos nivelada que la del hombre; sigue las tendencias propias de la localidad, sin contaminaciones exteriores. Es, digamos, más característica $y$, desde un punto de vista de sociología linguística, más espontánea.

En cuanto a la biología de los fenómenos fonéticos, la acción de la $s$ aspirada es más intensa sobre las consonantes sonoras que sobre las sordas (al revés, por ejemplo, de lo que ocurre en el Valais y en Valonia) y, de éstas, la más afectada por la acción es la velar sonora, seguida de la dental y, por último, de la bilabial. Hasta tal punto se pueden comprobar estos hechos, que el tratamiento de -sg-en el interior de una palabra llega a la metafonía total de la consonante sonora, sin permitir 1a identificación originaria.

Fonológicamente, la acción de la final sobre la inicial siguiente, no tiene repercusión cuando ésta es sorda $(p, t, k, s)$ o lateral o vibrante, pero sí cuando es una consonante sonora de tipo bilabial, dental o velar, en cuyo caso se puede llegar a oponer la inicial fricativa (la baca, etc.) como signo de singular, a la inicial oclusiva (la baca, etc.) como signo de plural. Essta realización alcanzará su auténtico valor significativo cuando ocurra, como en andaluz, una verdadera metafonia de $b, d, g$ (hacia $\varphi$. $\theta, h)$, que en el habla descrita en estas páginas sólo se cumple, y no con carácter imperativo, en el habla (parole) del informador que designamos $\mathrm{M}$.

29. Si la palabra siguiente empieza por vocal, la $-s$ anterior no se aspira, sino que se enlaza, sirviendo entonces como índice de plural: lo scírbole, la suña ( $\mathrm{HI}$ y $\mathrm{M}) \stackrel{2}{2}$.

30. Como observé en 'Tenerife ${ }^{3}$ y Gran Canaria y, con hondísima interisidad, en Lanzarote y Fuerteventura, en el habla de La Graciosa aparece una $\theta$ postinterdental, semejante a la de muchos sitios de Andalucía. Esta $\theta$ aparecía tanto en $H$ como en $M, y$ aunque su presencia coincidia con los casos que en castellano tienen interdental, la oi en otros casos no etimológicos. H y M pronunciaron con esa $\theta$ las siguientes

1 'Diferencias en el habla de Puebla de Don Fadrique (Granada). RFE, 1956, XL, pp. 28-3I y, con nuevos materiales, en Diferencias en el habla de hombres $y$ mujeres. "Revista do Livro", número I2, (1958), pp. 77-86.

2 Vid. D. CaTaIAN, lil español canario. Eintre lizropa y América. Bulellm de Filologia, IgGo, XIX, p. 323.

3 Tenerife, $\$ 26$. V., también, Canaris, p. $2 q^{2}$. 
voces del cuestionario: pedazo(s), lazo, acción. H seseó (y no la mujer), en susio, asul, aseite y en muchas voces que sólo pregunté a él (asuca diesisiete, luseru, sercu, aser, isar, balansea, bandaso y otros once casos en el vocabulario marinero); por el contrario, usó $\underline{\theta}$ postinterdental en diecinueve, vacian, enrcia, embozá 'almorzada', cecioso 'ceceoso', cecatri y otras quince palabras más. La M tuvo esa $\theta$ en tocino, picazo, garbanzo.

H. "ceceó" en braza 'brasa' (si es que no actuó sobre la mente del hablante. el término marinero) y $M$ en zuegra (forma alternante con suegra).

En el hombre recogi con frecuencia un sonido intermedio entre $s$ predorsal y $\theta$ postdental que apareció unas ocho veces a lo largo de la encuesta, mientras que en $M$ sólo se documentó una vez, y muy poco característica, en la $s$ - inicial de sucio.

3r. Hemos de pensar en un fonema que se realiza fonéticamente como $s$, como $z$, o como un sonido neutralizado.

La neutralización de $\mathrm{L}, y \mathrm{R}$

32. En posición implosiva la $l$ y la $r$ se neutralizaban en un archifonema que podía realizarse como $-l$, como $-r$, según se expondrá más adelante, podía desaparecer. La mujer dijo corchón (pero el $\mathrm{H}$, colchón), arcó (frente al hombre, alcól), alcu (pero $\mathrm{H}$, arco), borsillu (por bolsillu el hombre). El informador que designo por $\mathrm{H}$ solía hacer los infinitivos en -l (mientras que MI alargaba la vocal y perdía la consonante): bebel (M: bebé:), moril (M: morí), dehtetal, entregal, clarecel, etc. Fuera de estos casos, cl archifonema! se pronuncia como tal (calzonciIlo), como $r$ (sarpuyu 'salpullido', borza 'bolsa', carderu, er dote) o como $l$ (golguello 'garguero'). La neutralización de $-l$ y $r$ se da únicamente cuando la consonante es implosiva final de sílaba (en el interior o en la terminación de la palabra), pero no en cualquier otro caso. $Y$ aun en las ocasiones descritas el fenómeno por más que sea fácilmente documentable, carece de universalidad ${ }^{1}$.

\section{La $\mathrm{N}$ y las nasalizaciones}

33. En posición final absoluta, la $-n$ es velar $[\eta]^{2}$. En este caso la -n puede nasalizar intensamente a la vocal anterior, e incluso desaparecer. Así, testimouios como colch $\hat{\varphi}^{\dagger}$ ( $\mathrm{H}$ y M), $p \tilde{a}^{\eta}$ (ib.), holli $i^{\eta}$ (ib.),

1 Vid. Tenerife, § 29, y CATAI, $A$, p. 244.

- Toncrife, $\$ 33,1$, y Cataris, p. 242. 
aciọ̆n (ib.), etc., pueden aparecer al ludo de ehcalọ (H), porrọ́ (H), valentọ (H), sin duda menos frecuentes. No es imposible oir casos en los que la nasalización se da, aunque la $n$ no esté en posición final absoluta: êhwagwal 'enjuagar'.

34. En la persona Ellos del presente e imperfecto de indicativo y del presente e imperfecto de subjuntivo se puede producir una nasalización que incluso llega -o llegará- a tener carácter fonológico. Hoy la resonancia nasal no es significativa por cuanto se recogen otras posibilidades (como el mantenimiento de la $-n$ o su total desaparición, sin asomos de nasalización sobre la vocal). Por ejemplo: cohẹ $\tilde{e}^{\eta}$, cohiăn se oponen a cohe, cohiä, pero, Ellos cọha no se opone a Yo, El cọha, ni Ellos coliera a Yo, El cohiera. Sin embargo, son muchos los casos en los que la nasalización ha funcionado ya con carácter significativo: veniã, vinierã, asiã, riẽ, reiã, riãa, etc.

35. Hay una nasalización espontánea que se recoge en alguna ocasión como mall 'mar', piẽ 'pie' (ambas en M), que oídas fuera de contexto, parecen ser comparables a las de Gran Canaria: cafén y leche.

36. La nasalización es muy frecuente cuando ante una consonante nasal hay otra implosiva. Entonces se produce una asimilación a la nasal, que puede ser de muy diverso grado, desde la aspiración nasalizada

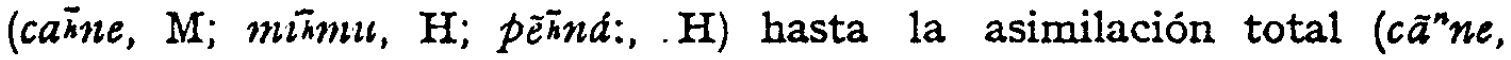
g a $\tilde{a}^{n} n a t e, s \tilde{a}^{n} n a$, bich $?^{n} n u$ 'bochorno', todos en $\left.\mathrm{H}\right)^{1}$.

\section{La LL, la Y y la CH}

37. Los dos informantes distinguían entre $l l$ y $y$. Tan sólo $\mathrm{H}$ pronunció algún raro caso de yeísmo: sarpıyı 'salpullido', oya 'olla' y algun oțro infrecuente testimonio. Lo normal, casi sin asomo de excepción, es distinguir entre la palatal lateral $(l l)$ y la palatal central $(y)^{2}$.

La $y$ era más abierta que la correspondiente del castellano y esta articulación, poco tensa, se documentó alguna vez, incluso en posición inicial absoluta (yerba 'hierba', $\mathrm{H}^{3}$ ).

38. La ch es la que suele señalarse como característica de las Islas: muy adherente, con una impresión acústica semejante a la de una $\hat{y}$

1 Para estos $\S \S 33-36$, vid. Tenevife, $\$ 33$.

2 Cir. Tenerife, $\S 32$, y CATALAN, pp. 243-244. Además, de este autor, Boletim de Filologia, XIX, pp. 326-328.

3 En Tenerife ( $\$ 3 I)$ la $y$ era más cerrada que la castellana. 
semisorda o parcialmente ensordecida. Lis, pues, una africada de amplia mojadura palatal y en la que el momento oclusivo es de una gran tensión y el fricativo llega casi a desaparecer. Mis dos informantes usaban de la misma $c h$ y no conocian otra ${ }^{1}$.

\section{Consonantes implosivas}

39. Amado Alonso 2 serialó la neutralización de ciertos rasgos pertinentes de las consonantes españolas cuando se encontraban en posición final absoluta. En el habla que describo, la neutralización puede llegar hasta la pérdida total de la consonante. Bien es verdad que suele tratarse de casos de polimorfismo por cuanto las formas con la consonante (relajada, neutralizada con otro sonido) alternan con las que careceu de ella.

I) Ell archifonema /S/ desaparece en almiré: (H y M), lii: (ib.), huç: (H), vQ̣: (H, pero vọ: $\left.{ }^{\wedge}, M\right)$; mientras que /s/ cae en máa 'más' (H y M),

2) La -r (para los infinitivos, vid, $\S 43$ ) cae en $m a \mathfrak{a}$ (M, frente a må:", H), flo: (M, frente a flol, H).

3) En cuanto a la $-l$ puede documentarse la pérdida (só:, $\mathrm{H}$; asu:, H; arc:ọ, M; mié:, H; hié:, M; arbu, H; foni, gandu:, H) frente a los de conservación (sol, M; azul, M; alcol, mięl, M; hiel, H). Los casos transcritos no permiten establecer ninguna diferencia entre mis dos hablantes: el estado caótico en que se presentan las distintas realizaciones fonéticas, muestra a las claras el carácter de polimorfismo de realizaciónes indiferentes $^{3}$ que se practica en estos casos.

\section{MOR FOLO G I A}

El nombre. El género

40. I) Los sustantivos en -ma son femeninos, aunque la lengus literaria mantenga la norma etimológica. Así se oye una pantahma, ahma mala, la sema 'el eczema' 4.

1 Tenerife, $\S 30$.

- Una ley fonológica del espaĩol. Hispanic Review, 1945, XIII y en los Estudios lingǘsticos. (Temas españolcs). Madrid, I95I. Vid., también, CaTALAN, p. 245 .

V. J. ALIIL̀riss. Le polymorphisme de l'-s implosive en gascon garonnais. "Via Domitian, I, 1954, p. 97.

- Tenerife, $\$ 40,2$. 
2) Han sido dotados de terminación femenina los sustantivos que poseen este género gramatical, pero carecian del morfema específico de género. Asi la chincha (cast. la chinche), la tilnna (cast. el un la tizne), lah liendra :las liendres' (todos en $\mathrm{H}$ y $\mathrm{M}$ ) ${ }^{1}$.

3) Por el contrario, persisten sustantivos en $-e$ (no incorporados a ningún grupo coin morfema caracterizador), masculinos unas veces (el vinagre, $l^{h}$ cline ${ }^{h}$ 'las crines'), pero otras femeninos (arfilé blanca, lah lente 'los lentes') '?.

4) Azuicar es femenino, como en muchas hablas. Lo mismo que sartén masculino ${ }^{3}$.

5) Cuando se trata de un nombre sustantivado, referido a mujeres, se ha impuesto como terminación la femenina: sirvientia, cri ${ }^{y}$ enta, parienta. Sin embargo, no se forman femeninos como *jueza, *médica, ni apellidos como *Calderona 'esposa de un hombre llamado Calderón'.

\section{El numero}

4I. Se usan con morfema de singular tijera, tenaza y pantalón: mientras que, en plural, tenazas.

Pronombres personales y reflexivos

42. Las formas recogidas son: yo, me; tú, te; él, se; losotro, lo; uhtedel ello, se. Las cliscrepancias con el castellano se explican por acción de la analogía (le se encuentra formando sistenia con me, te y presiona sobre nosotros, nos ${ }^{4}$ o por la pérdida de vos como forma de tratamiento entre iguales (de donde vos-otros) o como expresión de cortesia (para ceder el paso a usted) ${ }^{5}$.

$1 \quad I b$. . $\$ 40,3$.

2 Gafas es el término más corriente. Cfr. bibliografia que aduzco en Tenerife, página 5I, nota 120.

- Para el género de azúcar, v. A. Rosenblat, Vacilaciones y cambios de género. Boletin Instituto Caro y Cuervo, 1949, V, pp. 26-30. En cuanto a sartén, el masculino se atestigua en América, Asturias y judeo-español (Corominss, DCELC, s.v.).

- Vid. bibliografía en Tenerife, p. 52, zota 125; Catalán, p. 243.

- A. Rosenblat, Notas de morfología dialectal, en el tomo II de la *Biblioteca de Dialectologia Hispano-Americanan. Bucnos Aires, 1946, pp. 134-138. 
43. La -r del in $\mathrm{f}$ in i t i v o sigue la suerte de las consonantes inplosivas. Normalmente desaparece, dejando en compensación -cierto alargonicuto vocálico: trabahá: (H y M), bebé: (M), mori: (M), tormudá: (H), provocá: (id.), arrullá:, etc. Sin embargo, no es nada raro oir infinitivos en - $l$ : bebel, moril, elhtregal, torcel, ehcurecel 'oscurecer', etc, Menos frecuente, aunque no inusitada, es la conservación de la $-r$ bajo forma muy relajada: toca', molna e incluso maya'se. 'desmayarse'. Por razones de fonética sintáctica, esta $-r$ se puede conservar: beberal- aire.

Si el infinitivo va seguido de un pronombre enclítico, cabe ura asimilación parcial de la $-l$ a la del pronombre (hablalle), pero lo habitual es la eliminación de la consonante del infinitivo: cantale 'cantarle', secalu 'secario', y asocase 'guarecerse', huntase, artase, presinarse ${ }^{1}$.

Por últino, los infinitivos en -ear cierran la e en $i$ semiconsonántica: tosiar 'toser', albiá: 'albear, blanquear'.

44 Las desincncias del presente de indicativo han sufrido las siguientes transformaciones, a partir de las formas castellanas.

[Yo] -o: se realiza como o (coho, vengo, age, riọ, etc.)

['Tú] -s: suele desaparecer sin dejar rastro (cohe, viene, afloha, ase, etc.), o cierra a la vocal anterior (sale) o la abre (fregq 'friegas', güel $q$ ). En algún monosílabo, la aspiración se conserva muy relajada $\left(d a^{h}\right)$. Esta pluralidad de tratamientos, algunos rarísimamente documentados, muestra un polimorfismo fonético sin consecuencias morfológicas. Por tanto, la debilitación y pérdida de la $-s$ final no tiene carácter fonológico. Por otra parte, el único testimonio abundante de la suerte de esta -s es, precisamente, el de su total desaparición, con lo que la persona Tú parece abocada a su confusión con la persona El.

[El] $-a$ (.$^{a}$ conjugación), -e (.$^{a}$ y $3 .^{a}$ conjugaciones), no ofrecen ninguna particularidad de interés. Tan sólo en dos ocasiones, entre muchísimas, anoté una $-e$ con tendencia a cerrada.

[Nosotros] -annos (.$^{a}$ conjugación), -emos $\left(2 .{ }^{\mathrm{a}}\right)$, , imos (3. $\left.{ }^{\mathrm{a}}\right)$. La terminación -amos se realiza como -amo en los tres verbos que mi cuestionario documenta (aflojar, entregar, fregar); -emos sigue también la misma suerte (cierre de la o y pérdida de la -s: coger, hacer, oler), lo mismo que -imos (venir, reir, salir, etc.).

[Ellos] -an $\left(\mathrm{I} .{ }^{\mathrm{a}}\right)$, -en $\left(2 .^{\mathrm{a}}\right.$ y $\left.3 .{ }^{\mathrm{a}}\right)$ : dan lugar a los tratamientos des-

1 A. Alonso y R. LIDA, Geografla fonética: a-r y a implosivas en español. RFH, 1945, VII, y c1l los Fistudios Lingütsticos. (Temas hispanoamericanos). Madrid, 1953, pp. 196-331. Cfr. CatarÁn, p. 243. 
critos en el $\S .34\left(-\tilde{a}^{\eta},-\tilde{c}^{\eta} ;-\tilde{a},-\tilde{e}\right)$ con las posibles caracterizaciones morfofonológicas a que alli se hace mención.

45. Las desinencias del imperfecto de indicativo son:

[Yo] -ia: morfológicamente no ofrece particularidad alguna. Desde el punto de vista fonético, se da el paso -ia >-iä, descrito en el $\S \mathrm{I} 8$,I. Como en la misma situación está la persona Ėllos, se produce la misma homonimia que en castellano. Los verbos de la primera conjugación coinciden con la norma literaria.

[Tú] -abas ( $1 .^{\mathrm{a}}$ conjugación), -ias ( $2 .^{\mathrm{a}}$ y $\left.3 .{ }^{\mathrm{a}}\right)$ : la aspiración de la -s puede abrir la $-a$ precedente (palatalizada si hay una $i$ acentuada) en cohiä o, lo que es más frecuente, perderse sin ninguna compensación. Entonces, como ocurre en el presente de indicativo, se confunden Tú y El.

[E1] - $a b a(\mathrm{r} . \mathrm{a}),-i a\left(2 .{ }^{\mathrm{a}}\right.$ y $\left.3 .{ }^{\mathrm{a}}\right)$ : coinciden con la lengua oficial.

[Nosotros] -iamos $\left(2 .^{\mathrm{a}}\right.$ y $\left.3 .^{\mathrm{a}}\right)$ : tiene, fonéticamente, las realizaciones -iamo (cogiamo, asiamo, reiamos), -iámo (beniámo). En -ábamos no hay sino cenábamo.

[Ellos] -aban, -iban: coinciden en cuanto al tratamiento de la nasal con lo que he señalado en el presente de indicativo.

46. Las desinencias del pre se n te de $s u b$ j $u$ t i vo dan lugar a las siguientes consideraciones:

[Yo] -e ( $I^{\mathrm{a}}$ conjugación), $-a\left(2 .^{\mathrm{a}}\right.$ y $3^{\mathrm{a}}$ ): la $-e$ es media (como en castellano) o cerrada (caso éste menos frecuente); la $-a$ no ofrece ninguna particularidad. Esto, unido a la pérdida de $-s$ en la persona Tú, hace que, en muchos casos, coincidan todas las personas del singular.

[Tú] -es ( $1 .^{a}$ conjugación), -as $\left(2 .^{a}\right.$ y $\left.3 .^{a}\right)$ : se pronuncian $-e, a-$, respectivamente. Hay algun caso de $-a$ (coha, venga, riqu) o de $-\ddot{a}$ (agä), pero dominan las formas neutralizadas.

[El] - $e$ ( $\mathrm{r}^{\mathrm{a}}$ conjugación), $-a\left(2 .^{\mathrm{a}}\right.$ y $\left.3 .^{\mathrm{a}}\right)$ : carecen de diferencias con respecto al español normal.

[Nosotios] -emos ( $I^{a}$. conjugación), -amos $\left(2 .^{a}\right.$ y $\left.3 .{ }^{a}\right)$ : no se atestiguan traslados acentuales del tipo *entréguemos, *fréguemos en ningún verbo de la primera conjugación'. Sin embargo, cólhamo, ágamo (frente a golamo 'olamos') y véngaino, sárgamo 'salgamos' (frente a riamo y conduhcamo) muestran que el proceso también existe en La Graciosa, aunque tales formas alternen con las castellanas.

1 A. Alonso ejemplifica siempre con verbos en -er o -ir, pero al establecer las causas que determinan el fenómeno, piensa en otras analogfas cumplidas en los verbos en -ar (Cfr. Problemas de Dialectologia Hispanoamericana. Buenos Aires, I930, pp. 37-4 I, y, especialmente, la 40). I.os datos de La Graciosa coinciden con los de Tenerife, $\S 44, \mathrm{I}$. 


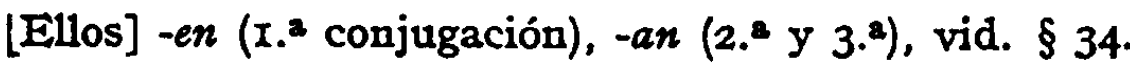

47. El i m perfect o de $s u b j u n t i v o$ emplea siempre la desinencia -ra. El paradigma completo es: -era; -era/-erq; -era; -aramol -jéramo; -iera $\tilde{a}^{\eta} /$ -

48. Las desinencias de $f u t u$ ro pueden unirse a la terminación verbal sin producir síncopa de la vocal del infinitivo (saliré, -irá, -irá) ${ }^{2}$, pero, junto a este hecho, hay otras personas verbales que coinciden con las castellanas (saldremo, -dn). Ni traịré, ni pondré ofrecen interés.

49. El condicional de salir es, como en muchos pueblos andaluces, saldria, -ia, -iä, -iamo, - $\left\{\hat{a}^{\eta}\right.$ i; mientras que son normales traịria, etc., y pondria, etc.

\section{Presentes irregulares}

50. Algún verbo tiene su $\mathrm{p}$ resente de in $\mathrm{f}$ in itivo distinto del castellano, y coincidente con los dialectos occidentales: roir 'roer', hervé 'hervir' 4.

5r. En el presente de indicativo documenté las siguientes anomalías:

I) la persona Tú del verbo reir es $r i$ :, acaso variante polimórfica de ría, documentada para El (Tú te rie $>$ rie $>r i)^{5}$.

2) no diptongan (ui en el presente de indicativo, ni en el de subjuntivo) las formas fuertes de fregar (frego, fregas, fregar, etc.), ni las de cntregar (entrego, etc.; entregue, etc.).

3) un verbo en -ucir que figura en el cuestionario se conjugó así en el presente de indicativo: conduho 'conduzco' ', conduce 'conduces' conduce, -ducimo, -ducẹ. Mientras que, en el de subjuntivo, aparecieron las formas castellanas (conduhca, etc.), salvo en la persona Ellos, donde se oyó la terninación -iza, propia de los incoativos leoneses.

4) no hay ninguna anomalia en los presentes de indicativo y de subjuntivo de oler, dar, medir, pedir y decir.

1 En las encuestas del ALEA, éstas han sido las únicas formas documentadas.

- Como en español autiguo y Santo Domingo (Rosenslat, Notas, ya citadas, p. 234).

- Son fornas analógicas, segúw señala Rosenbrat (Notas, 'p. 234).

- Vid. Tenerife, p. 54, nota 134 (roir). Herver es arcaico, del occidente peninsular y de América (Rosinbl,AT, Notas, p. 219, nota).

- Vid. Tenerife $\$ 45$.

- Creo que esta forma se explica de este modo: de un *conduzgo, frecuente en la época clísica y en los dialcctos, saldria el seseante *condusgo y de él, por fonćtica normal dentro del liabla que nos ocupa, conduho (v. § 27,3). 
Desinencias del perfecto de indicativo

52. Los datos recogidos se ordenan del siguiente modo:

[Yo] -é (I. conjugación), -i $\left(2 .^{\mathrm{a}}\right.$ y $\left.3^{\mathrm{a}}\right)$ : no ofrecen ünguna particularidad.

[Tú] -aste (r.a conjugación), -iste (2.a y $3^{a}$ ): el tratamiento de la $s$ implosiva hace que pueda haber dualidad fonética $(-t e,-t e)$, pero sin resultados para la morfología (allegáte 'llegaste', anda:te 'anduviste'; cohite 'cogiste', vinite 'viniste', de una parte, y reitte, isitte, de otra). En mis materiales son muchísimo más abundantes las formas -ate, -ite que las $-i^{i} t e$ (no hay $-a^{i} t e$ ).

[E1] - 6 : alternan, sin otro valor que el puramente fonético, las realizaciones $-\dot{\sigma},-o \underline{\text {. }}$.

[Nosotros] -amos (.$^{2}$ conjugación), -imos (2. ${ }^{\mathrm{a}}$ y $\left.3 . \mathrm{a}\right)$; como en tantas hablas vulgares, -amos, bajo la influencia de la primera persona, se convierte en la desinencia analógica -emo (alleguemo 'llegamos') ${ }^{1}$. Mientras que -imos sólo sufre las alteraciones producidas por la pérdida de la $s$ final (\$26): unas veces se realiza como-imo y otras - las menos- como -imo.

[Ellos] -aron ( $r .^{a}$ conjugación), -ieron $\left(2 .^{a}\right.$ y $\left.3 .^{a}\right)$ : son de consignar, únicamente, las alternancias sufridas por la -0 final, según se nasalice y cierre (llegarọ), se cierre sin nasalizar (viero), se nasalice sin cerrar (vinierd) o se pierda la nasal sin dejar rastro (detuviero). Cuatro posibilidades que indican otras tantas realizaciones fonéticas, carentes de sentido para la morfonología.

No he racogido nunca la $-n$ conservada.

Perfectos irregulares

53 Por más que el antecedente del español insular sea el castellano, voy a ordenar los perfectos siguiendo la formación latina. Obtendremos, así, una sistematización cómoda y fácil de comparar.

I) perfectos fuertes: venir, hacer y ver no presentan ninguna particularidad, salvo las que afectan a la pronunciación, tratadas ya.

2) perfectos en -s $i$ : reir, decir, componer no se apartan de la norma castellana; traer documenta la forma trahiero, etimológica y muy extendida por todo el dominio del español ${ }^{2}$. Maldecir se aparta del modelo simple para formar todo el perfecto sobre el tema de presente: maldeci, -decite, -dició, -decimo, -diciero.

1 Vid. Tenerife, $\$ 46,6$, y CATALAN, p. 243.

2 Vid. Rosenblat, Nolas, pp. 296-298, especialmente. 
3) p e r f e c t o s en - 26 : detener es como en castellano; mientras que andar sigue, unas veces, la analogía vulgar $y$, otras, se incorpora a la conjugación culta: ande, andate, anduvo, anduvimo, anduvieron.

4) el perfecto de ir es fi, fite, fue 1 .

5) cl pretérito perfecto de indicativo se forma, como es de esperar con haber, pero la primera persona es Yo á (tenio, etc.) ${ }^{2}$.

Particulas

54. En mis materiales sólo anoté las siguientes discrepancias con respecto a la lengua oficial: sigúu, acigựn 'según' y arentọ 'adentro'.

\section{S I N T A X I S}

55. En el cuestionario hay 23 frases cuya "traducción" al habla local se propone al informador. Se trata, pues, de una serie de calas en diversos aspectos de la oración, que pueden dar cierta idea de las preferencias idiomáticas del informador $y$, por ende, del dialecto. Para quien investiga es ésta la parte más penosa de sus pesquisas y la que - sobre el terreno- presenta mayor número de dificultades. Precisamente por tales riesgos, sentidos por todos los lingüistas que se dedican a este tipo de trabajos, reduje en mi cuestionario las preguntas sintácticas a unas cuantas muestras de valor muy preciso e inequívoco.

56. La c o m p a a ción de igualdad se hace igual que en castellano (... como...). A la pregunta concreta del cuestionario, uesto es verde como..." el iuformador respondió la pintura, porque en su mundo mental el verde se asocia al color del que ve cubiertos los barquichuelos.

Cuando se trata de establecer una comparación de $s$ u $p$ e r i o r i d a d con carácter absoluto, las respuestas obtenidas fueron perifrasis con muy (muy guapa 'guapísima') o adjetivos en los que va implicita la ponderación en su grado extremo: una piña hermosa 'una mazorca grandísima'.

57. El orden reflexivo t-personal es el de la lengua literaria (se me cayó, se te pasó). En cuanto a se como índice de pasiva refleja, la norma era vacilante: el informador dijo una vez se cortaron dos árboles, interpretando correctamente dos árboles como sujeto del verbo, mientras que en otro caso dijo se vende ovejas, considerando ovejas como com-

1 Como en Mréjico, Argentina, Murcia (Rosendrat, Notas, p. 37, nota).

- Forma documentada en Nuevo Méjico, Santo Domingo, Cuba (Rosenstar, Notas, p. 294, § 242) y ell Andalucia. 
plemento. Este concepto de se como exponente de la idea de la impersonalidad se percibe también en frases del tipo se m'importa un pito 'me importa un pito'. Pues si me mantiene su carácter de dativo ético, se no tiene otro sentido que el de introducir un periodo totalmente impersonal.

58. Los u s o s de los tiempos del verbo, según mis datos, e insisto en su carácter muy limitado, ofrecieron las siguientes particularidades:

r) En vez del pretérito perfecto de indicativo se usa el perfecto absoluto para indicar una anterioridad inmediata: "esta mañana fui al mercado" (= "... he ido...»), "toa la tarde bailé» (= "we bailado toda la tarde"), "se aogó un niño" (= "se ha ahogado...")"

2) En deterninadas oraciones $\mathrm{cond}$ i c i o n a $1 \mathrm{es}$, la prótasis se coustruye en imperfecto de subjuntivo (forma en -ra), mientras que la apódosis puede ir en imperfecto de indicativo (usi tú entraras, yo me salia") o en condicional ("si tuvicra dinero, lo compraria»).

3) Para indicar la idea de perfección con respecto a un tiempo también futuro, se emplea, como en castellano, el presente de subjuntivo en la oración temporal y el futuro simple en la principal: "cuando tú venga, ya yo lo tendré hechol.

4) Como en otras hablas meridionales el futuro simple es sustituido con frecuencia por el presente de indicativo y el condicional por el imperfecto.

5) Expresiones desiderativas del tipo "ojalá llueva", "ojalá lloviera" no son sentidas en su matiz diferencial: el informador dio, en uno y otro caso, la equivalencia dialectal, aholá lloviera.

\section{O N C L U S I O N E S}

Caracteres del habla

59. I a lengua hablada en I a Graciosa participa de los rasgos propios del español canario. Dentro de estas caracteristicas estarian $x$ ) el alargamiento de las vocales acentuadas, 2) la $s$ predorsal, 3) la aspiración de la $s$ implosiva, 4) la existencia de una aspirada faríngea o laringea, 5) la $n$ velar en posición final absoluta, 6) ciertos tipos de nasalizaciones, 7) la ch muy adherente, 8) la neutralización de las consonantes implosivas interiores y finales, 9) las formas pronominales losotros los, Io) la pérdida de vosotros y su repercusión en el verbo, II) el perfecto -emos (por -amos), I2) la no diptongación de algunos verbo

1 V. CA'IAIAN, p. 247. 
(frego), I3) traslación acentual en el presente de subjuntivo (véngamo, sárgamo), I4) los usos del pretérito perfecto de indicativo en vez del perfecto absoluto, 15) cierta repugnancia al empleo del futuro de indicativo y del condicional y I6) la tendencia a sustituir el condicional por el imperfecto de indicativo en las oraciones condicionales.

Cierto que estos rasgos pueden no ser exclusivamente canarios $y$. cierto también, hay otras particularidades que no he recogido. Pero en un primer inventario de hechos indiscutibles, todos los que he consignado pertenecen a esa parcela del español meridional que son las hablas de las Islas Canarias.

60. Ahora bien, he registrado otros muchos elementos que sirven -también- para caracterizar el español de $I_{r} a$ Graciosa, aunque su presencia no hable de un particularismo meridional, concierna a lenguas distintas de la nuestra o hayan pasado desapercibidos el hablar de los dialectos españoles. Para situar estos hechos y, a la vez, para definir el habla descrita en lincas anteriores, conviene confrontar los materiales allegados con otros geográficamente muy próximos. En las lineas que siguen, compararé el habla de I,a Graciosa con la de Haría, el punto más próximo que he estudiado en la isla de I,anzarote con el mismo cuestionario del ALEICan ${ }^{1}$.

6r. El vocalismo de La Graciosa presenta una articulación de -o final, que puede llegar al cierre en $-u$ ( $\S \S 9-I 0)$. En este sentido se habian aducido rasgos de otras islas ( $L_{\text {a }}$ Palma, Tenerife), pero carecíamos de una descripción sistemática de los hechos $y$, lo que es más de lamentar, de una información coherente y fidedigna.

Al llevar a cabo cada encuesta, anoto las peculiaridades fonéticas que se destacan de la lengua común. Son, pues, datos de carácter impresionista que deben ser estudiados minuciosamente más tarde. Sin enubargo, su interés queda reflejado en esa misma anotación. En el cuaderno de Haria tengo escritas unas líneas que transcribo con absoluta fidelidad 2: "La -0 final era extraordinariamente cerrada, hasta

1 Mis informantes fuerou: 1) Marcial González Cerpa, agricultor, de 32 años analfabeto que no habia salido de su pueblo, en el que nacieron sus padres y su mujer. 2) Angel Perdomo González, de 42 años, también labrador, poseía una instrucción muy elemental. El, su padre y su esposa eran de Haria; su madre, de Teguise en la propia isla.

Aún hice una encuesta de pescadores en Orzola, frente a La Caleta del Sebo. A ella me referiré más adelante.

2 Para aclarar una alusión que hago en ellas debo consignar que la encuesta de Haria es anterior a la de I a Graciosa; por eso consigné los informes que recogt en Lanzarote sobre la isla que aún me era desconocida. Al citar, no rectifico en mada la redacción apresurada con que hice mis auotaciones. 
el extremo que en M. G. [informador Marcial González] lo que se percibía era una $u$ con muchísima frecuencia. En el sujeto A. P. [Angel Perdomo], tal cierre no era tan sistemático, pero tampoco escaseaba el grado $u$ del primer informador. Este rasgo aparecía también en una mujer instruida de 40 años con la que hablé mucho, porque en su casa hice las encuestas. Al parecer es rasgo de todo el extremo norte de la isla y de I a Graciosan. El marinero de Orzola pronunció -o.

$\mathrm{Ni}$ en la Caleta del Sebo, ni en Haría, esta $u$ final tenía carácter fonológico, pues, con frecuencia, y en ambas localidades, se podía registrar - $\imath$ en casos donde otras hablas abren la vocal final. Así, por ejemplo, en los plurales y en el verbo ( $\S$ Io). Se trata, pues, de una realización fonética del fonema $/ O /$ que puede tener unas veces la variante $o$ y otras la variante $u$. El hecho de que ambas formas se den en un mismo hablante o en hablantes distintos, pero siempre con el valor neutralizado de $-o=-\imath$, hace pensar en hechos polimórficos de realizaciones indiferentes. Unidos estos testimonios a los del $\S \mathrm{I2}$, se puede inferir que hay tendencia a la articulación cerrada de la 0 (incluso pronunciada $u$ ) aunque no se pueda hablar todavía del valor fonemático de esta $u$ frente a la 0 -. El proceso parece estar más desarrollado en las mujeres (La Graciosa) y en la gente más tosca (Haria), aunque es necesario llevar a cabo encuestas específicas sobre el hecho. De momento, se puede pensar que el aislacionismo del habla de las mujeres y la incontaminación de las gentes más incultas han favorecido el desarrollo de este rasgo.

62. El cierre de la -e final era menos sistemático que el de la -0 , por más que sea un proceso paralelo. Aparecía esta $-e>i$ no sólo en las palabras terminadas en sílaba libre, sino también en casos en los que existió una $-s$ trabante. Los comentarios hechos a la $-o$ podrían repetirse aquí (vid. además los $\S \S \mathrm{I} 4-\mathrm{I} 5$ ), pero quiero ahorrar repeticiones. Baste parangonar está realización fonética con la que se da al norte de Lanzarote; en mi cuestionario de Haría escribi: "En cuanto a la -e final, M. G. la cerró con frecuencia en $e, \mathrm{y}$ esporádicamente A. P., pero no creo que, por lo que of y por lo que transcribi, se pueda hablar del paso $-e>i$, que me decian se daba por esta zona». Tanto en La Graciosa como en Haria, el proceso está en marcha, aunque - al parecer- se ha desarrollado más en el islote septentrional, sobre todo en el habla de las mujeres. O dicho de otro modo, en el tratamiento de $-e>i$ el habla de los hombres ha alcanzado unia nivelación media más uniforme que la de las mujeres.

63. Si carecía de carácter fonológico la dualidad de timbre en vocal final tanto en la seric palatal como en la velar, tampoco tiene valor de oposición el paso $-a>\ddot{a}$ que se puede dar en algunos plurales (vid. $\S$ I8, 
I-3). También en Haría, -as podía realizarse como $a$ o como $a^{d}$, pero nunca con un valor intencional. Es, pues, un hecho fonético como el de $i \ldots a, e ́ . . . a>\{\ldots a ̈, e ́ . . . \ddot{a}$, que se da en la isla de Gran Canaria y con mayor intensidad en toda la de Lanzarote. Tampoco ahora cabe separar el habla de La Graciosa de la de Haría, en la que, como en tantas ocasiones, ha vueito a coincidir.

64. No tiene correspondencia en el habla de Haria la neutralización de $/ \mathrm{K} /$ y $/ \mathrm{G} /$ en posición explosiva. El informador H de La Graciosa las realizó unas veces con el archifonema ${ }_{g}^{k}$ y otras con $k$ y $g$, alófonos combinatorios ( $\S 22)$. Es cierto que el fenómeno parece estar todavía en un grado difuso de realización, pero no por eso deja de ofrecer interés suficiente para hacernos cargo de él en estas conclusiones.

Por lo que respecta a otras consonantes, la $f$ era bilabial en La Graciosa ( $\$ 23$ ) y en Haría; la pérdida de la $-d-$ intervocálica ( $(24)$ era sistemática en las dos hablas $y$ también en ambos sitios recogí una $\theta$ postdental. En Haría anoté, con referencia a la articulación de $s$ y $\theta:$ : $[\mathrm{L}$ a distinción entre $s / \theta$, , ] no tenía carácter general e imperativo, pero surgía con una enorme frecucucia. 'lenian $\theta$ M. G., A. P. [mis dos sujetos] y otxo hombre (57 años aproximadamente) que asistió a la segunda de mis sesiones de trabajø. Essta $\theta$ aparecia con alguna insistencia en la mujer de 40 años, a la que ya he hecho mención [\$60]».

65. En el tratamiento de la $s$ implosiva ( $\S I_{5-28}$ ) los hechos polimórficos son de una gran variedad, aunque, por su propia naturaleza, carezcan de valor fonológico ( $\$ 28$ ). En Haria la inestabilidad de los grupos precedidos por $s>h$ era también muy grande; como resultados más frecuentes anoté: $s b>t^{\phi}, s d>\vec{a}, s g>h, s y>{ }^{k} \hat{y}$. Son. éstas soluciones que se encuentran dentro de las líneas de evolución que he señalado en los $\S \S 26-28$, si es que no coinciden totalmente con ellos.

66. Ya queda dicho ( $\$ 37)$ que los dos hablantes de La Graciosa distingúan entre $l l$ y $y$. Algún rarísimo testimonio de yeísmo se deslizó en el habla de $\mathrm{H}$, pero no consiguió desvirtuar la imagen muy nítida que tieven alli de las dos palatales. Pero este hecho no es siempre de igual claridad en el habla de las Islas Canarias; antes bien, hay una entreverada distribución de elles y yes que difícilmente pueden someterse a un sistema. Normalmente, los núcleos más aislados y rústicos mantienen el arcaísmo de la distinción, mientras que la vida urbana y el habla de los cultos impone la neutralización de los rasgos distintivos. Un buen testimonio de estos hechos se refleja en los materiales que poseo de Haría. Allí la situación es verdaderamente caótica: un viejo de 82 años que asistió a mis tres sesiones de trabajo (era el padre de la casa donde hice las encuestas) distinguía entre $l l$ y $y$, por más que en alguna rara 
ocasión practicara el yeísmo. Por el contrario, un hombre de 57 años que estuvo en la segunda sesión distinguió siempre, lo mismo que un pastor de Maguez, pueblecito cercano a Haria. No distinguian ni la mujer de 40 años, a la que me he referido algunas veces, ni el informante Marcial González, ni un pescador de Orzola (50 años) al que pregunté todos los asuntos concernientes al mar. Mi otro sujeto, Angel Perdomo, era yeista, aunque de vez en cuando, y siempre en proporción muy escasa, prouunció $l l$.

Asl, pues, La Graciosa mantiene un arcaísmo fonético que parece estar desplazado, o en trance de desaparición, en los puntos más próximos de Lanzarote, salvo en el habla de gentes muy arcaizantes por el carácter de sus ocupaciones (por ejemplo, el pastor de Maguez). El resultado de esta desfonologización de $l l$ ha conducido, en algunos hablantes de Haria, a la creación de un polimorfismo que pudiéramos llamar de realizaciones indiferentes.

67. Por último, entre los rasgos que he anotado del español hablado en $\mathrm{I}$ a Graciosa merecería la pena señalar algunos que no han tenido cabida en estas conslusiones: I) la terminación de los infinitivos (vocal larga, vocal +1 , asimilación y pérdida de la $-r$ a la consonante inicial de los pronombres enclíticos, $\S 43), 2$ ) desinencia -mos convertida en -mo ( $(44), 3)-i a(s)$ que pasa a $-i a ̈$, como en la fonética nominal $(\S 45)$, 4) -te como desinencia de la persona Tú en el perfecto absoluto $(\S 5 \mathrm{I}), 5)$ algunos perfectos anómalos $(\S 52), 6)$ en el indicativo, empleo del perfecto absoluto en vez del perfecto compuesto $(\S 57, \mathrm{I})$, 7) empleo del imperfecto por el condicional $(\S 57,2)$ y del presente por el futuro $(\S 57,4)$.

68. Si de todos estos rasgos quisiéramos extraer un resumen caracterizador, podríamos concluir que el español de I, a Graciosa participa de los caracteres fonéticos y morfológicos que son propios de la lengua hablada en las Islas Canarias (vid. §58). Sus rasgos están en intima conexión con los que hemos documentado en algún punto del norte de Lanzarote ( $\$ \S 60-64)$, aunque, en cierto sentido, su lengua ofrece una arcaísmo mayor ( $\$ 65)$ y presenta algunos rasgos de polimorfismo que, por su realización ocasional, no pueden interpretarse como caracteres independizadores ( $\$ 64)$.

Manuei, Aivar.

Universidad de Granada. 